\title{
Acrylamide Mitigation in Fried Kochchi Kesel Chips Using Free and Immobilized Fungal Asparaginase
}

\section{Aiswarya Ravi and \\ Baskar Gurunathan*}

Department of Biotechnology, St. Joseph's College of Engineering, 600119 Chennai, India

Received: July 14, 2017 Accepted: December 14, 2017
*Corresponding author:

Phone: +914424501060;

E-mail: basg2004@gmail.com

ORCID IDs: 0000-0002-6176-8078 (Ravi), 0000-0003-1061-421X (Gurunathan)

Paper was presented at the 7 th International Forum on Industrial Bioprocessing - IFIBiop 2017, May 21-24, 2017, Wuxi, PR China

\begin{abstract}
SUMMARY
Acrylamide is formed when food products are fried at high temperature. Food researchers are constantly working on developing efficient methods for mitigating acrylamide in fried foods. In the present study, asparaginase from Aspergillus terreus was used for the pretreatment of kochchi kesel banana slices before frying to mitigate acrylamide formation during frying. The soaking and frying conditions were optimized using free and chitosan-immobilized asparaginase. The optimal soaking temperature and time were found to be $60^{\circ} \mathrm{C}$ and $20 \mathrm{~min}$, respectively. The optimal activity of free and chitosan-immobilized asparaginase was found to be $5 \mathrm{U} / \mathrm{mL}$. The optimal frying temperature and time for both free and chitosan-immobilized asparaginase were found to be $180^{\circ} \mathrm{C}$ for $25 \mathrm{~min}$ with an acrylamide mass fraction of 1866 and $954 \mu \mathrm{g} / \mathrm{kg}$, respectively. The kinetics and thermodynamics of enzymatic mitigation of acrylamide in kochchi kesel chips were also studied. It was concluded that the chitosan-immobilized asparaginase pretreatment of kochchi kesel slices is an effective method for mitigation of acrylamide.
\end{abstract}

Key words: acrylamide mitigation, activation energy, asparaginase, kochchi kesel, chitosan

\section{INTRODUCTION}

Acrylamide is formed due to Maillard reaction when food products are fried at high temperature of above $120^{\circ} \mathrm{C}(1)$. The presence of asparagine in starchy foods has been found to increase the concentration of acrylamide in fried foods (2). Acrylamide is a carcinogenic agent and induces various cancers. The change in lifestyle and type of food consumption among the consumers has created a great demand for fried and baked foods. Due to changes in the nutritional value of fried and baked foods, people are prone to many non-communicable diseases including obesity, diabetes and cancer (3). The exposure to acrylamide and its effects in cells, tissues, animals and humans has been extensively studied. The investigation on human neurotoxicity to acrylamide exposure showed that the activity of glutathione S-transferase (GST) in brain was inhibited with the increase in brain dopamine concentration. It was reported that acrylamide was well absorbed and distributed widely in tissues on oral administration (4). Food researchers around the world are in the process of establishing a valid strategy for the mitigation of acrylamide concentration in fried foods. Several methods such as the addition of divalent cations and replacement of reducing sugar have been adopted for enhancing the mitigation of acrylamide in fried foods $(5,6)$. Blanching or soaking of food products in acids, cations, amino acids and enzymes before frying minimizes the interaction of asparagine with starch and reduces the acrylamide formation (7). The use of asparaginase cleaves the asparagine present in starchy foods into aspartic acid and ammonia by the inhibition of Schiff's base. In recent years, the influence of hydrocolloids on acrylamide reduction has been constantly tested with various food systems. The hydrocolloidal coating of pectin and alginic acid has been proven to decrease the acrylamide content by approx. $50 \%$ when incorporated in crackers (8). 
The percentage of acrylamide reduction using hydrocolloids differs with respect to the food matrix. The free amines present in the chitosan compete with the asparagine, which implies the reduction of acrylamide $(9,10)$. The interaction of amine-rich chitosan and the asparagine modulates the acrylamide formation.

During the Maillard reaction the influence of temperature and time plays a significant role in the formation of acrylamide. The mitigation of acrylamide in fried kochchi kesel chips follows the first order kinetics. The integrated first order reaction rate is given in the following equation:

$$
\ln \left(c / c_{0}\right)=-k \cdot t
$$

where $c_{0}$ is the initial concentration of acrylamide ( $\left.\mathrm{mol} / \mathrm{L}\right)$ at time zero, $c$ is the concentration of acrylamide ( $\mathrm{mol} / \mathrm{L}$ ) formed with respect to time $t$ ( $\mathrm{min}$ ) and $k$ is rate constant (11). Acrylamide mitigation is mainly influenced by temperature and time; the relationship is correlated with an Arrhenius plot for better understanding of the energy required for the reaction to proceed. The reaction rate and the temperature dependence are given in the following equation:

$$
k(t)=k_{0} \cdot \exp \left(-\frac{E_{\mathrm{a}}}{R \cdot T}\right)
$$

where $k$ is rate constant, $t$ is time ( $\mathrm{min}), E_{a}$ is activation energy $(\mathrm{J} / \mathrm{mol}), R$ is gas constant $(\mathrm{J} /(\mathrm{mol} \cdot \mathrm{K}))$ and $T$ is temperature $(\mathrm{K})$. Thus, the present work aims to evaluate the influence of free asparaginase pretreatment and chitosan-immobilized asparaginase as a novel strategy for acrylamide mitigation in kochchi kesel chips.

\section{MATERIALS AND METHODS}

\section{Materials}

Kochchi kesel banana sample was procured from a local market, Chennai, India. L-Asparagine, phosphate buffer, Tris$-\mathrm{HCl}$ and L-proline were obtained from HiMedia laboratories Pvt. Ltd., Mumbai, India. The chemicals used for Czapek-Dox agar slants, as well as glutaraldehyde and trichloroacetic acid were purchased from Loba Chemie Pvt. Ltd, Mumbai, India. Acetic acid and Nessler's reagent were obtained from Chemspure, Chennai, India. Chitosan of analytical grade was purchased from Qualigens Fine Chemicals, Mumbai, India. The Whatman No. 2 filter paper was purchased from Sigma-Aldrich, Bengaluru, India. HPLC grade chemicals such as acetonitrile and $n$-hexane were purchased from Merck, Mumbai, India. Primary secondary amine (PSA) and magnesium sulfate were purchased from Agilent, Bengaluru, India.

\section{Production of L-asparaginase}

The Aspergillus terreus MTCC 1782 was obtained from Council for Scientific and Industrial Research, Institute of Microbial Technology, Chandigarh, India. The stock cultures were cultivated in Czapek-Dox agar slants and stored at $4{ }^{\circ} \mathrm{C}$ and subcultured monthly. L-Asparaginase was produced by submerged fermentation of $A$. terreus in modified Czapek-Dox liquid medium with a composition (in $\%$ by mass per volume): L-proline 2 , L-asparagine 1 , glucose 0.2 , sodium nitrate 1 , potassium chloride 0.052 , dipotassium hydrogen sulfate 0.152 , zinc sulfate 0.001 , copper sulfate 0.001 , ferrous sulfate 0.001 and magnesium sulfate 0.052 , and maintained at $\mathrm{pH}=6.2$. The fungus was grown aerobically by continuous agitation in an orbital shaker at $30 \times g$ (Orbitek ${ }^{\circledR}$ LT; Scigenics Biotech Pvt. Ltd., Chennai, India) at $32^{\circ} \mathrm{C}$ for 4 days. The fermentation broth was filtered using Whatman No. 2 filter paper and the cell-free filtrate was used as crude asparaginase solution (12).

\section{Assay of asparaginase activity}

The asparaginase activity was determined using Nesslerization method (13). A volume of $0.1 \mathrm{~mL}$ of asparaginase was mixed with $0.9 \mathrm{~mL}$ of $0.1 \mathrm{M}$ phosphate buffer and $1 \mathrm{~mL}$ of $0.04 \mathrm{M} \mathrm{L}$-asparagine. This mixture was incubated at $37^{\circ} \mathrm{C}$ for $10 \mathrm{~min}$ and the reaction was stopped by adding $0.5 \mathrm{~mL}$ of $15 \%$ trichloroacetic acid. The solution was mixed thoroughly and centrifuged at $1125 \times g$ (C-24BL; Remi Laboratory Instruments, Maharashtra, India) for $10 \mathrm{~min}$ at $4{ }^{\circ} \mathrm{C}$. A volume of 0.1 $\mathrm{mL}$ of supernatant was diluted to $8 \mathrm{~mL}$ using distilled water, and then $1 \mathrm{~mL}$ of $2 \mathrm{M} \mathrm{NaOH}$ and Nessler's reagent were added. The mixture was incubated for $10 \mathrm{~min}$ at $28^{\circ} \mathrm{C}$ and the absorbance was measured at $480 \mathrm{~nm}$ with spectrophotometer (model 166; Systronics Pvt. Ltd., Chennai, India).

\section{Synthesis of chitosan nanobiocomposites of asparaginase}

The commercial chitosan (0.01\%) was added to $0.05 \%$ acetic acid and continuously stirred for $1 \mathrm{~h}$. Then, $1 \mathrm{M} \mathrm{NaOH}$ $(5 \mathrm{~mL})$ was added to the solution to precipitate chitosan and the precipitate was washed with distilled water until neutral $\mathrm{pH}$ was obtained. The synthesized suspension was activated with $1 \%$ glutaraldehyde for $3 \mathrm{~h}$ at $32{ }^{\circ} \mathrm{C}$. The suspension was ultrasonicated in ultrasonic water bath ( $\mathrm{PCl}$ Analytics, Maharashtra, India) for $15 \mathrm{~min}$ to reduce the size of the particle and then centrifuged at $1887 \times g$ (C-24BL; Remi Laboratory Instruments) for $10 \mathrm{~min}$. The particles were washed with $50 \mathrm{mM}$ Tris $\mathrm{HCl}$ buffer $(\mathrm{pH}=8.5)$ for complete removal of unreacted glutaraldehyde. The pretreated chitosan suspension was mixed with fungal asparaginase for $30 \mathrm{~min}$ at $32^{\circ} \mathrm{C}$ and was centrifuged at $1887 \times g$ for $10 \min (9,10,14,15)$. The specific activity of free and immobilized asparaginase was estimated. The percentage of binding of asparaginase on chitosan was found to be $70.35 \%$.

\section{Optimization of pretreatment and frying conditions}

The skin of kochchi kesel sample was removed. The plantain was cut into uniform slices, which were washed with distilled water to remove the excess starch adhered on the surface and pretreated with free and chitosan-immobilized asparaginase suspension for the optimization of different 
pretreatment parameters such as time, temperature and asparaginase concentration. The pretreated slices were washed thoroughly with deionized water for the complete removal of residues. The frying parameters such as frying time and temperature were studied at different conditions in an air fryer (3.5 L; Pigeon, Chennai, India). The acrylamide concentration in fried kochchi kesel chips was estimated using high-performance liquid chromatography (HPLC model 1260 Infinity; Agilent Technologies, Waldbronn, Germany).

\section{Extraction of acrylamide from fried kochchi kesel chips}

The extraction of acrylamide from kochchi kesel fried chips was carried out using Agilent QuEChERS method $(16,17)$ by spiking $1 \mathrm{~g}$ of powdered kochchi kesel fried chips with internal standard. The solvents $n$-hexane $(5 \mathrm{~mL})$ and acetonitrile $(10 \mathrm{~mL})$ were used for the extraction along with $9 \mathrm{~mL}$ of HPLC grade water. Then, $4 \mathrm{~g}$ of magnesium sulfate and $0.15 \mathrm{~g}$ of sodium chloride were added and centrifuged at $755 \times g$ (C-24BL; Remi Laboratory Instruments) for 5 min. After centrifugation, the obtained upper hexane layer was discarded. The remaining solution was mixed with ISOLUTE ${ }^{\circledR}$ (Biotage $A B$, Uppsala, Sweden), PSA, C18EC (a retentive, non-polar sorbent for extraction of a range of analytes from aqueous samples) and $\mathrm{MgSO}_{4^{\prime}}$ and then centrifuged at $755 \times \mathrm{g}$ for $5 \mathrm{~min}$. A volume of $1000 \mu \mathrm{L}$ of the extracted solution was transferred into HPLC autosampler vial for acrylamide estimation $(16,17)$.

\section{Quantification of acrylamide in fried chips by HPLC}

The acrylamide concentration in kochchi kesel fried chips extract was carried by HPLC equipped with quaternary pump and a diode array detector (1260 Infinity; Agilent Technologies). The separation of the compound was carried by ZORBAX HILIC Plus column ( $4.6 \mathrm{~mm} \times 50 \mathrm{~mm}, 3.5 \mu \mathrm{m}$ particle size) and the data were processed by Agilent Chemstation for LC/MS 2D software (17). The flow rate and temperature were maintained during the analysis at $0.2 \mathrm{~mL} / \mathrm{min}$ and $30^{\circ} \mathrm{C}$, respectively, with injection volume of $5 \mu \mathrm{L}$. The mobile phase was $3 \%$ acetic acid and $97 \%$ acetonitrile with the run time and post time of 10 and 3 min, respectively (18). The calibration curves were constructed by plotting the peak area against the concentration and the mass fraction of acrylamide was calculated with respect to the obtained peak area.

\section{Characterization of synthesized nanocomposite and fried kochchi kesel chips}

The synthesized chitosan-immobilized asparaginase was characterized by proton nuclear magnetic resonance spectroscope ('H-NMR, model AVANCE III; Bruker, Rheinstetten, Germany) to determine the chemical shifts confirming the presence of amine group in chitosan particle with asparaginase. The surface characteristics of fried kochchi kesel chips were characterized by scanning electron microscope (SEM, model Quanta 200; ThermoFisher Scientific, Hillsboro, OR,
USA) and the presence of functional group was characterized by Fourier-transform infrared spectroscope (FTIR model RFS 27; Bruker). The thermal characteristics of the fried chips were studied using differential scanning calorimeter (DSC model STA 449; Netzsch, Selb, Germany).

\section{RESULTS AND DISCUSSION}

\section{${ }^{1} \mathrm{H}$-NMR characterization of chitosan-immobilized asparaginase}

The change in chemical shift due to immobilization of asparaginase on chitosan was studied by ${ }^{1} \mathrm{H}-\mathrm{NMR}$. The two signals of ${ }^{1} \mathrm{H}$ are noted with different chemical shifts, as shown in Fig. 1. The peak at 2.484 ppm confirms the presence of $\mathrm{NH}_{2}$ group, indicating the confirmation of chitosan particle. The strong secondary peak from 2.36 to 2.53 ppm confirms the binding of carboxamide in asparaginase with amine group of chitosan. The peak in the anomeric region shows the exact characteristics of the composite material. The doublet peak at the anomeric region shows the exact characteristics of composite material noted with split of $\mathrm{O}-\mathrm{H}$ groups. The presence of these peaks reveals the high degree of substitution of carboxylic group with the chitosan, as shown in Fig. 1.

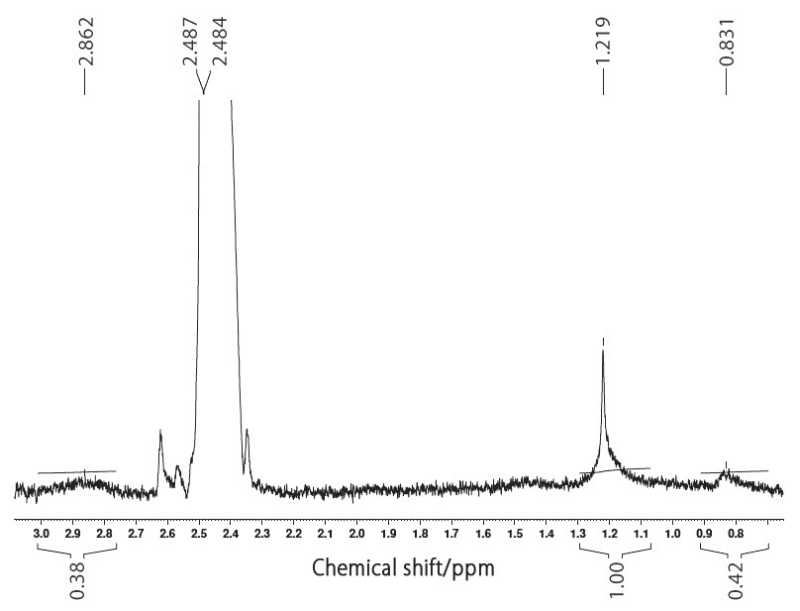

Fig. 1. 'H-NMR spectrum of chitosan-immobilized asparaginase

Effect of soaking time and temperature on acrylamide mitigation in fried kochchi kesel chips using asparaginase

The effect of soaking time and temperature on acrylamide mitigation in kochchi kesel fried chips was studied using free and chitosan-immobilized asparaginase solution. The soaking temperature was varied at 20,40 and $60^{\circ} \mathrm{C}$. The soaking time was varied from 10 to $25 \mathrm{~min}$ with an interval of $5 \mathrm{~min}$. The activity of both free and chitosan-immobilized asparaginase solutions was fixed at $4 \mathrm{IU} / \mathrm{mL}$. Acrylamide mass fraction in fried chips was decreased with increase in soaking temperature and time, as shown in Fig. 2. The lowest acrylamide mass fraction of $1322 \mu \mathrm{g} / \mathrm{kg}$ was obtained after $20 \mathrm{~min}$ of soaking time at $60^{\circ} \mathrm{C}$. The decrease in acrylamide mass fraction with increase in soaking temperature and time might 


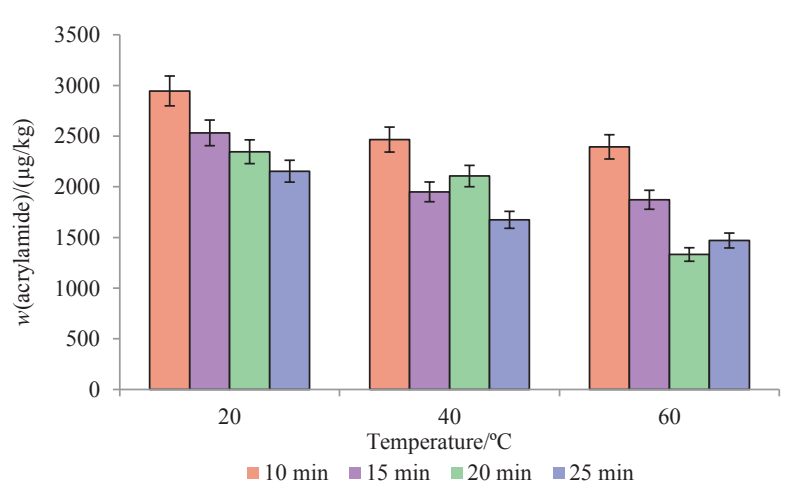

Fig. 2. Effect of soaking temperature and time on acrylamide mitigation in kochchi kesel fried chips using asparaginase

be due to the increase in hydrolysis of asparagine in kochchi kesel slices.

\section{Effect of free and chitosan-immobilized asparaginase on acrylamide mitigation in fried kochchi kesel chips}

The effect of free asparaginase and chitosan-immobilized asparaginase was studied for the effective mitigation of acrylamide in fried kochchi kesel chips. The activity of both free and chitosan-immobilized asparaginase was varied from 1-6 U/mL with fixed frying temperature at $180^{\circ} \mathrm{C}$, soaking time of $20 \mathrm{~min}$ and pretreatment temperature at $60^{\circ} \mathrm{C}$. The increase in both free and chitosan-immobilized asparaginase activity decreased the acrylamide mass fraction in fried chips (Fig. 3). The acrylamide mass fraction of $1158 \mu \mathrm{g} / \mathrm{kg}$ was obtained when using $5 \mathrm{U} / \mathrm{mL}$ of asparaginase immobilized on chitosan. The acrylamide mass fraction of $1872 \mu \mathrm{g} / \mathrm{kg}$ was obtained when using free asparaginase at $5 \mathrm{U} / \mathrm{mL}$. Thus, $5 \mathrm{U} / \mathrm{mL}$ of chitosan-immobilized asparaginase was optimal and more effective in acrylamide mitigation than free asparaginase. This might be due to the competitive interaction of free asparagine with the amines of chitosan.

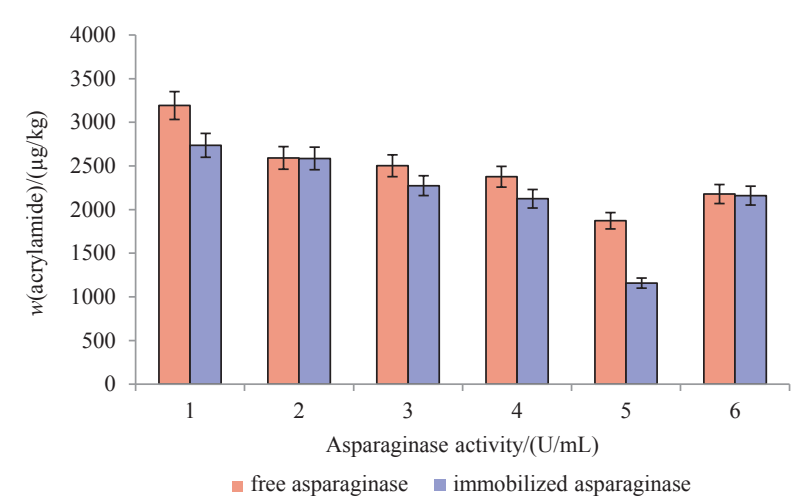

Fig. 3. Effect of free and immobilized asparaginase on acrylamide mitigation in kochchi kesel fried chips

\section{Effect of frying temperature and time on acrylamide mitigation in kochchi kesel chips}

The effect of frying temperature and time on acrylamide mitigation in fried kochchi kesel chips was studied after pretreatment for $20 \mathrm{~min}$ at $60^{\circ} \mathrm{C}$ with $5 \mathrm{U} / \mathrm{mL}$ of free asparaginase, free chitosan and chitosan-immobilized asparaginase. The frying temperature and time were varied from $160-200^{\circ} \mathrm{C}$ and 20-30 min, respectively. The acrylamide mass fraction in fried kochchi kesel chips treated with free asparaginase at different frying temperatures and time is shown in Fig. 4a. The highest mass fraction of acrylamide $(3372 \mu \mathrm{g} / \mathrm{kg})$ was found after treatment at $160{ }^{\circ} \mathrm{C}$ for $30 \mathrm{~min}, 3126 \mu \mathrm{g} / \mathrm{kg}$ were found after treatment at $180{ }^{\circ} \mathrm{C}$ for $20 \mathrm{~min}, 2616 \mu \mathrm{g} / \mathrm{kg}$ was found after $30 \mathrm{~min}$ at $200^{\circ} \mathrm{C}, 2250 \mu \mathrm{g} / \mathrm{kg}$ was found after $30 \mathrm{~min}$ at $180^{\circ} \mathrm{C}$ and the lowest mass fraction of $1506 \mu \mathrm{g} / \mathrm{kg}$ after 25 min at $180^{\circ} \mathrm{C}$. The acrylamide mass fraction in fried kochchi kesel chips treated with chitosan-immobilized asparaginase at different frying temperatures and time is shown in Fig. 4b. The highest mass fraction of acrylamide $(2886 \mu \mathrm{g} / \mathrm{kg})$ was found after $20 \mathrm{~min}$ at $160^{\circ} \mathrm{C}, 2238 \mu \mathrm{g} / \mathrm{kg}$ were found after 20 $\min$ at $200{ }^{\circ} \mathrm{C}, 1974 \mu \mathrm{g} / \mathrm{kg}$ were found after $20 \mathrm{~min}$ at $180^{\circ} \mathrm{C}$ and the lowest mass fraction of $954 \mu \mathrm{g} / \mathrm{kg}$ was obtained after $25 \mathrm{~min}$ at $180^{\circ} \mathrm{C}$.

The acrylamide mass fraction in fried kochchi kesel chips treated with free chitosan at different frying temperatures and time is shown in Fig. 4c. The highest mass fraction of acrylamide $(2532 \mu \mathrm{g} / \mathrm{kg})$ was found after $20 \mathrm{~min}$ at $160{ }^{\circ} \mathrm{C}, 2034 \mu \mathrm{g} /$ $\mathrm{kg}$ were found after $25 \mathrm{~min}$ at $180^{\circ} \mathrm{C}, 2238 \mu \mathrm{g} / \mathrm{kg}$ were found after $20 \mathrm{~min}$ at $200^{\circ} \mathrm{C}$ and the lowest mass fraction of $1512 \mu \mathrm{g} /$ $\mathrm{kg}$ was obtained after $30 \mathrm{~min}$ at $180^{\circ} \mathrm{C}$. The control sample without any pretreatment was also examined to compare the effectiveness of asparaginase pretreatment (Fig. 5). The acrylamide mass fraction was found to increase with the increase in time and temperature, with the lowest mass fraction of 3134 $\mu \mathrm{g} / \mathrm{kg}$ obtained after $20 \mathrm{~min}$ at $160^{\circ} \mathrm{C}$ and highest mass fraction of $3551 \mu \mathrm{g} / \mathrm{kg}$ after $30 \mathrm{~min}$ at $200^{\circ} \mathrm{C}$ (Fig. 5). The increase in the acrylamide mass fraction at the optimal temperature might be due to the loss of stability and charring of fried chips. The lowest mass fraction of acrylamide obtained using free asparaginase, chitosan-immobilized asparaginase and free chitosan was 1506, 954 and $1512 \mu \mathrm{g} / \mathrm{kg}$, respectively (Fig. 4). Thus, the chitosan-immobilized asparaginase was the most effective in mitigation of acrylamide in kochchi kesel chips when frying them at $180^{\circ} \mathrm{C}$ for $25 \mathrm{~min}$.

When comparing the acrylamide mass fraction in fried kochchi kesel chips $(954 \mu \mathrm{g} / \mathrm{kg}$ ) with literature, there are very few reports available on mitigation of acrylamide levels in banana/plantain products $(19,20)$. The maximum acrylamide range in raw plantain chips and banana fritters was reported to be $1690.5-3585 \mu \mathrm{g} / \mathrm{kg}$. The use of free asparaginase was reported to reduce acrylamide mass fraction to $1536 \mu \mathrm{g} / \mathrm{kg}$ (19-21). The effect of free chitosan and asparaginase did not show significant reduction in the mass fraction of acrylamide. This might be due to loss of amine group and the issues related to the stability of free asparaginase. Thus, the use of 


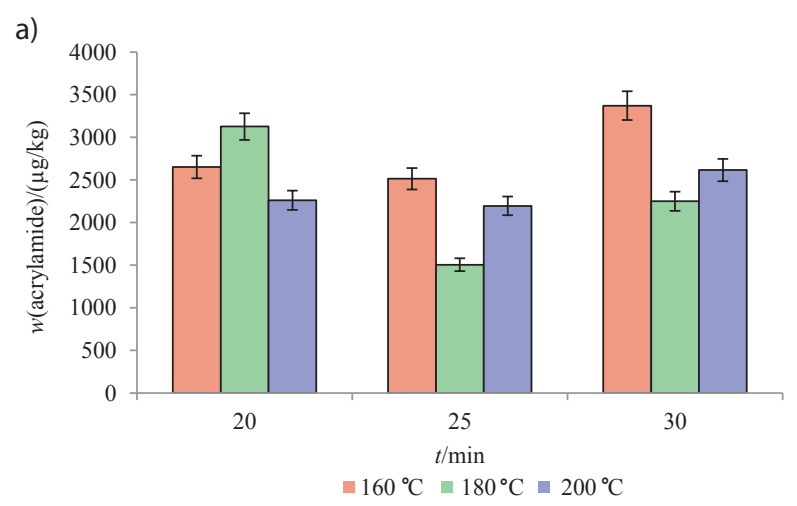

b)

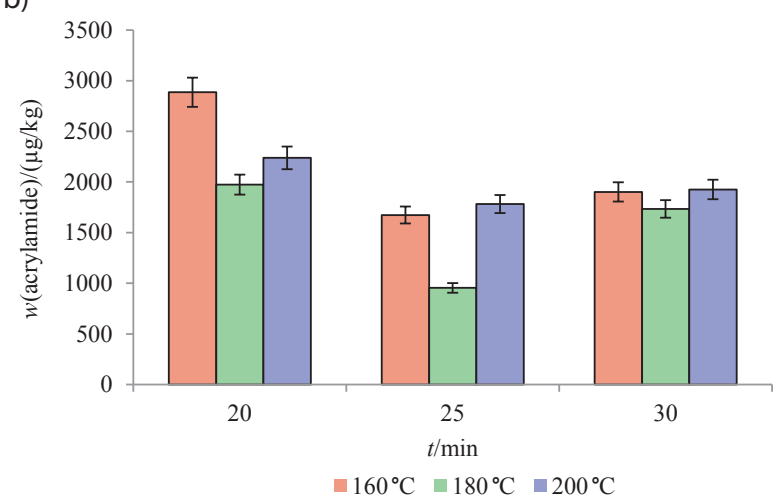

c)

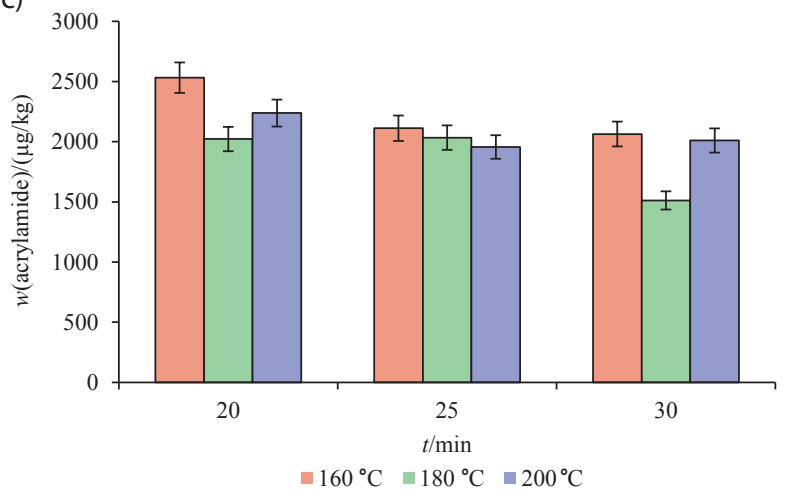

Fig. 4. Effect of frying temperautre and time on acrylamide mitigation in fried kochchi kesel chips using: a) free asparaginase, b) chitosan-immobilized asparaginase, and c) free chitosan

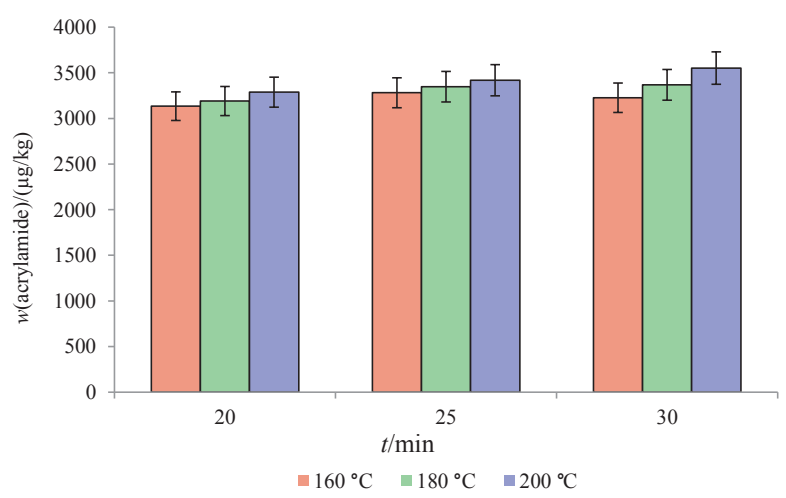

Fig. 5. Effect of frying temperature and time on acrylamide mitigation in fried kochchi kesel chips without pretreatment chitosan-immobilized asparaginase has proven to be an effective approach for acrylamide mitigation in fried kochchi kesel chips.

\section{Kinetics and thermodynamics of acrylamide mitigation in fried kochchi kesel chips}

The acrylamide mitigation in fried kochchi kesel chips followed the first order reaction kinetics, which was evident from correlation coefficient greater than 0.9. Fig. 6 shows the Arrhenius plot for acrylamide mitigation by asparaginase in fried kochchi kesel. The plot Ink vs. 1/T confirms the linear nature of acrylamide mitigation. The study of activation energy, $E_{a^{\prime}}$ shows the influence of temperature on acrylamide formation. This study helps to understand the strong interference between reducing sugar and its intermediates. The activation energy, $E_{\mathrm{a}}=18067.15 \mathrm{KJ} / \mathrm{mol}$ confirms the strong influence of temperature on acrylamide mitigation.

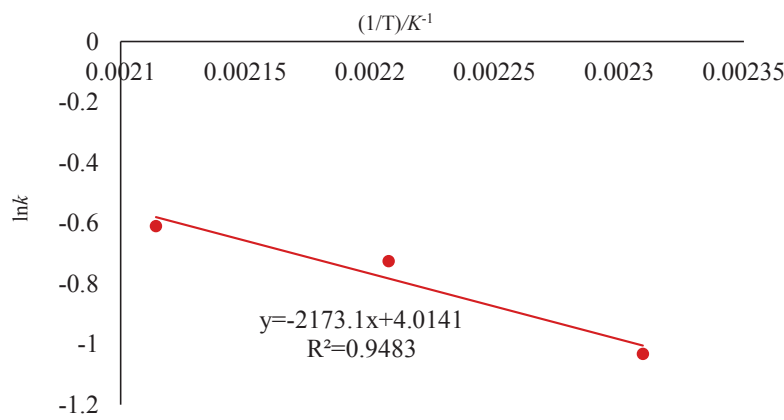

Fig. 6. Arrhenius plot of acrylamide mitigation by asparaginase in fried kochchi kesel chips

\section{Characterization of fried kochchi kesel chips treated with asparaginase}

The surface characteristics of fried kochchi kesel chips were studied by scanning electron microscopy. Fig. 7a shows the surface of fried kochchi kesel chips treated with asparaginase, which was found to be smoother and more porous in nature than of untreated fried chips. The porosity of fried chips pretreated with asparaginase was regular with homogeneous surface in nature, which shows that asparaginase influenced the surface characteristics. Fig. 7b shows the untreated fried chips, found with irregular and non-porous surface characteristics.

The presence of chemical groups in fried kochchi kesel chips was studied by Fourier transform infrared spectroscopy (FTIR). The spectrum of asparaginase-treated fried kochchi kesel chips shows the trace amount of amine group at peak $1746 \mathrm{~cm}^{-1}$ noted with lower intensity at the $\mathrm{C}=\mathrm{O}$ stretching region (blue line in Fig. 8), whereas the spectrum of untreated chips was noted with higher intensity of amine group at $\mathrm{N}-\mathrm{H}$ stretching and in the fingerprint region (pink line in Fig. 8). The trace amount of amine reveals that the asparaginase has 

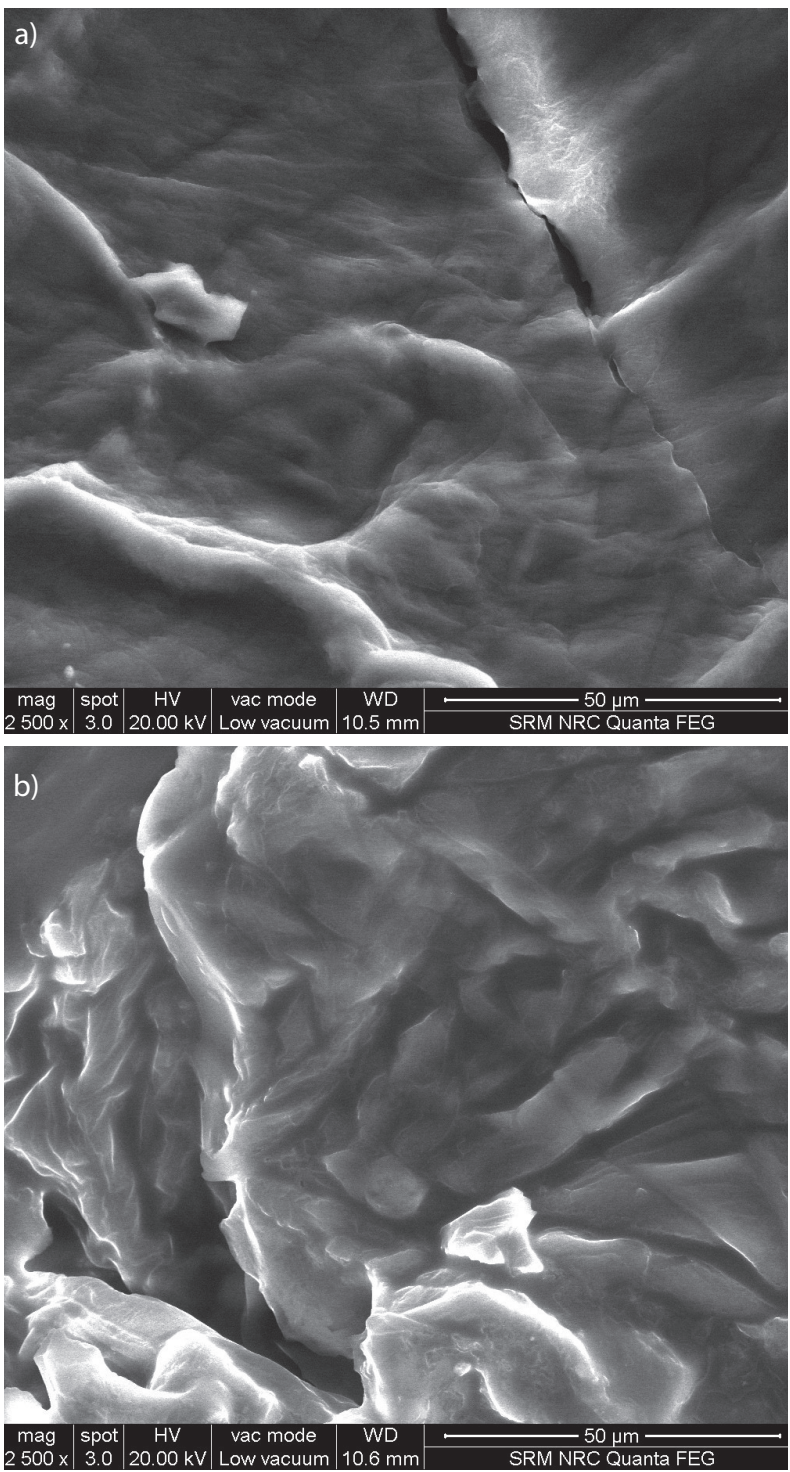

Fig. 7. Scanning electron microscopy (SEM) image of fried kochchi kesel chips: a) treated with asparaginase, and b) untreated

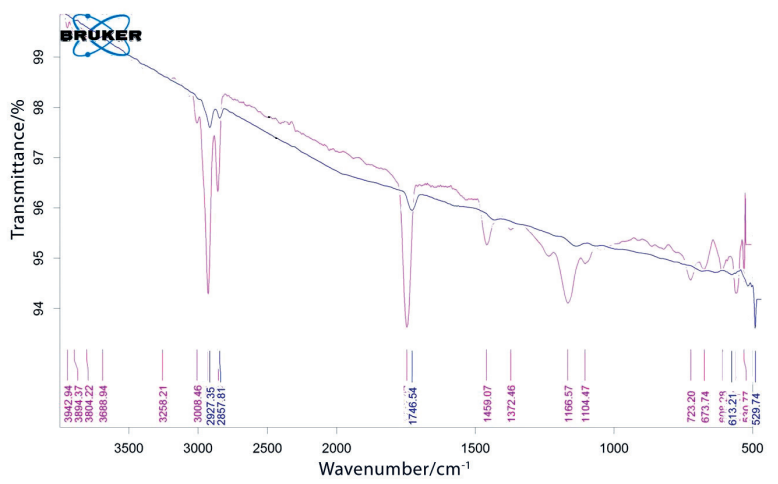

Fig. 8. FTIR spectrum of fried kochchi kesel chips treated with asparaginase (blue line) and untreated (pink line)

influenced the mitigation of acrylamide by its strong interaction with the amine group of asparagine present in raw kochchi kesel slices during pretreatment. Thus, this confirms that the asparaginase has influenced the reduction of acrylamide in fried chips.

The change in the characteristics of fried chips was studied using differential scanning calorimeter (DSC). DSC analysis is one of the functional analyses carried out in the food industries to study the thermal properties as they greatly influence the food characteristics. Fig. 9 shows the DSC of asparaginase-treated (red line) and untreated (blue line) fried chips. The larger peak area in the untreated fried chips shows that there is high desolvation when compared to the treated fried chips. The smaller peak area of the asparaginase-treated fried chips confirms the low desolvation, thus the fried chips of the treated samples absorb limited heat and have lower calorific value.

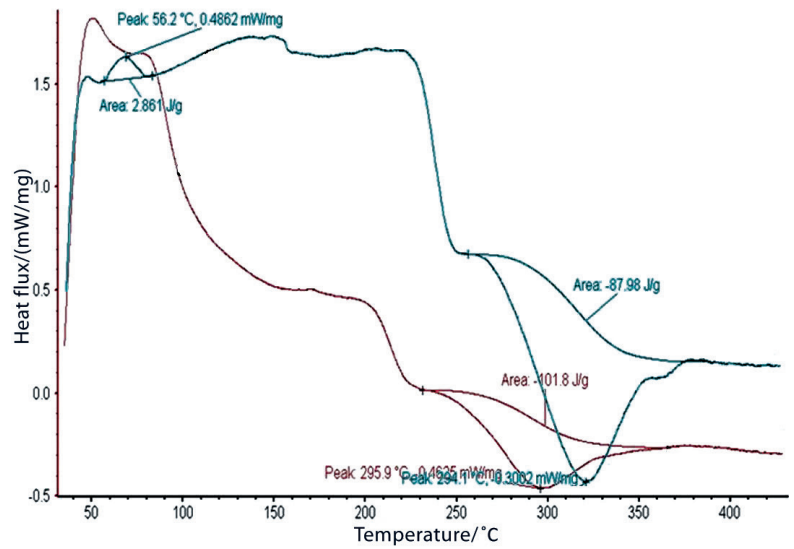

Fig. 9. Differential scanning calorimetry (DSC) spectrum of fried kochchi kesel chips treated with asparaginase (red line) and untreated (blue line)

\section{CONCLUSIONS}

The chitosan-immobilized asparaginase has shown pronounced action in the mitigation of acrylamide in fried kochchi kesel banana chips. The mitigation of acrylamide in fried kochchi kesel was efficient with acrylamide mass fraction of $954 \mu \mathrm{g} / \mathrm{kg}$ when using asparaginase-immobilized chitosan after frying for $25 \mathrm{~min}$ at $180^{\circ} \mathrm{C}$. The synergistic effect of asparaginase and chitosan increased the acrylamide mitigation level. The kinetic and thermodynamic studies revealed the strong relationship between temperature and acrylamide mitigation. The characterization results also confirmed the positive effect of chitosan-immobilized asparaginase on the mitigation of acrylamide and changes in the characteristics of fried kochchi kesel chips.

\section{ACKNOWLEDGEMENT}

This work was financially supported under the Scheme of StartUp Research Grant (Young Scientists, Engineering Sciences, File No. YSS/2014/000170) by Science and Engineering Research Board, Department of Science and Technology, Government of India. 


\section{REFERENCES}

1. Becalski A, Lau BPY, Lewis D, Seaman SW. Acrylamide in foods: Occurrence, sources, and modeling. J Agric Food Chem. 2003;51(3):802-8. https://doi.org/10.1021/jf020889y

2. Medeiros Vinci R, Mestdagh F, De Meulenaer B. Acrylamide formation in fried potato products - Present and future, a critical review on mitigation strategies. Food Chem. 2012;133(4):1138-54.

https://doi.org/10.1016/j.foodchem.2011.08.001

3. Ouhtit A, Al-Sharbati M, Gupta I, Al-Farsi Y. Potato chips and childhood: What does the science say? An unrecognized threat? Nutrition. 2014;30:1110-2. https://doi.org/10.1016/j.nut.2014.01.008

4. Hogervorst JG, Schouten LJ, Konings EJ, Goldbohm RA, van den Brandt PA. Dietary acrylamide intake and the risk of renal cell, bladder, and prostate cancer. Am J Clin Nut. 2008;87(5):1428-38.

5. Gökmen V, Şenyuva HZ. Acrylamide formation is prevented by divalent cations during the Maillard reaction. Food Chem. 2007;103:196-203. https://doi.org/10.1016/j.foodchem.2006.08.011

6. Amrein TM, Schönbächler B, Escher F, Amadò R. Acrylamide in gingerbread: Critical factors for formation and possible ways for reduction. J Agric Food Chem. 2004;52:4282-8. https://doi.org/10.1021/jf049648b

7. Zeng X, Cheng KW, Jiang Y, Lin ZX, Shi JJ, Ou SY, et al. Inhibition of acrylamide formation by vitamins in model reactions and fried potato strips. Food Chem. 2009;116(1):34-9. https://doi.org/10.1016/j.foodchem.2009.01.093

8. Zeng X, Cheng KW, Du Y, Kong R, Lo C, Chu IK, et al. Activities of hydrocolloids as inhibitors of acrylamide formation in model systems and fried potato strips. Food Chem. 2010;121(2):424-8. https://doi.org/10.1016/j.foodchem.2009.12.059

9. Chang YW, Sung WC, Chen JY. Effect of different molecular weight chitosans on the mitigation of acrylamide formation and the functional properties of the resultant Maillard reaction products. Food Chem. 2016;199:581-9. https://doi.org/10.1016/j.foodchem.2015.12.065

10. Sansano M, Castelló ML, Heredia A, Andrés A. Acrylamide formation and quality properties of chitosan based batter formulations. Food Hydrocolloid. 2017;66:1-7. https://doi.org/10.1016/j.foodhyd.2016.10.019
11. Mulla MZ, Annapure US, Bharadwaj VR, Singhal RS. A study on the kinetics of acrylamide formation in banana chips. $J$ Food Process Preserv. 2016;41:e12739. https://doi.org/10.1111/jfpp.12739

12. Baskar G, Renganathan S. Statistical and evolutionary optimisation of operating conditions for enhanced production of fungal L-asparaginase. Chem Pap. 2011;65(6):798-804. https://doi.org/10.2478/s11696-011-0072-8

13. Wriston Jr JC, Yellin TO. L-asparaginase: A review. Adv Enzymol Relat Areas Mol Biol. 1973;39:185-248. https://doi.org/10.1002/9780470122846.ch3

14. Bahreini E, Aghaiypour K, Abbasalipourkabir R, Mokarram AR, Goodarzi MT, Saidijam M. Preparation and nanoencapsulation of L-asparaginase II in chitosan-tripolyphosphate nanoparticles and in vitro release study. Nanoscale Res Lett. 2014;9:340.

https://doi.org/10.1186/1556-276X-9-340

15. Singh AN, Singh S, Suthar N, Dubey VK. Glutaraldehyde-activated chitosan matrix for immobilization of a novel cysteine protease, procerain B. J Agric Food Chem. 2011;59:6256-62. https://doi.org/10.1021/jf200472x

16. Oracz J, Nebesny E, Żyżelewicz D. New trends in quantification of acrylamide in food products. Talanta. 2011;86:23-34. https://doi.org/10.1016/j.talanta.2011.08.066

17. Pule BO, Torto N. Determination of acrylamide in cooking oil by Agilent Bond Elut QuEchERS Acrylamide kit and HPLC-DAD (Application Note). Santa Clara, CA, USA: Agilent Technologies; 2012.

18. Geng Z, Wang P, Liu A. Determination of acrylamide in starch-based foods by HPLC with pre-column ultraviolet derivatization. J Chromatogr Sci. 2011;49:818-24. https://doi.org/10.1093/chrsci/49.10.818

19. Daniali G, Jinap S, Zaidul SIM, Hanifah NL. Determination of acrylamide in banana based snacks by gas chromatography-mass spectrometry. Int Food Res J. 2010;17:433-9.

20. Shamla L, Nisha P. Acrylamide in deep-fried snacks of India. Food Addit Contam Part B Surveill. 2014;7:220-5. https://doi.org/10.1080/19393210.2014.894141

21. Pedreschi F, Mariotti S, Granby K, Risum J. Acrylamide reduction in potato chips using commercial asparaginase in combination with conventional blanching. LWT - Food Sci Technol. 2011;44;1473-6. https://doi.org/10.1016/j.lwt.2011.02.004 